\title{
Robust and Flexible Hydrocarbon Production Forecasting Considering Heterogeneity Impact for Hydraulically Fractured Wells
}

\author{
Hadi Parvizi ${ }^{\dagger},{ }^{*}$ Sina Rezaei-Gomari ${ }^{\dagger}$, and Farhad Nabhani ${ }^{\dagger}$ \\ $\dagger$ Teesside University, Tees Valley, Middlesbrough TS1 3BX, United Kingdom
}

\begin{abstract}
Producing oil and gas from increasingly more difficult reservoirs has become an unavoidable challenge for the petroleum industry as the conventional hydrocarbon resources are no longer able to maintain the production levels corresponding to the global energy demand. As the industrial investments in developing lower-permeability reservoirs increase and more advanced technologies such as horizontal drilling and hydraulic fracturing gain more attention and applicability, the need for more reliable means of production forecasting also become more noticeable. Production forecasting of hydraulically fractured wells is challenging particularly for heterogeneous reservoirs where the rock properties vary dramatically over short distances, significantly affecting the performance of the wells. Despite the recent improvements in well performance prediction, the issue of heterogeneity and its effects on well performance have not been thoroughly addressed by the researchers and many aspects of heterogeneity have yet remained unnoticed. In this paper, a novel empirical approach for production forecasting of multi-fractured horizontal wells is presented in attempt to effectively include the effect of heterogeneity. This approach is based on the integration of hyperbolic Decline Curve Analysis (DCA) and heterogeneity impact factor (HIF). This newly-defined ratio quantifies the heterogeneity impact on the hydraulically fractured well performance and is calculated based on net-pressure match interpretation and post-fracture well test analysis. The proposed approach of decline curve using heterogeneity impact factor $(\mathrm{DCH})$ is validated against data from a Southern North Sea field. The results show a maximum of $15 \%$ difference between the outcome of the proposed method and the most detailed three-dimensional historymatched model, for a 15-year period of production forecasts. DCH is a novel, fast, and flexible method
\end{abstract}


for making reliable well performance predictions for hydraulically fractured wells and can be used in forecasting undrilled wells and the range of possible outcomes caused by the heterogeneity.

Keywords. Heterogeneity, Hydraulic Fracturing, well performance, forecasting, tight formation, empirical correlation

\section{INTRODUCTION}

The ever-increasing demand for sources of energy has made it inevitable for oil and gas companies to strive for producing the more difficult reservoirs with very low permeabilities with the aid of advanced technologies such as horizontal drilling and hydraulic fracturing. These technologies are aimed at increasing the contact of the well with the producing zone to create effective flow paths for hydrocarbons locked away in these low permeability reservoirs ${ }^{1}$, thus obtaining economical production rates. Performance prediction of the wells drilled in such reservoirs has, therefore, gained significant importance.

Since the experimental investigation on the efficiency and feasibility of well production is tedious, expensive, and, in some cases, unsuccessful in finding reliable results, different methodologies for forecasting production wells have been developed and published. Based on empirical relationships of production rate versus time, Arps $(1945)^{2}$ introduced the decline curve analysis (DCA) method which was later augmented by type curves by Fetkovich $(1980)^{3}$. This method, which consists of the exponential, hyperbolic, and harmonic models, has been further improved ${ }^{4,5,6,7,8,9,10}$ and frequently used in the industry for a long time.

Several authors investigated the performance prediction of horizontal wells for different flow models $^{11,12,13,14,15,16,17}$. Other authors modified the vertical well fracture performance models to be used for

horizontal wells ${ }^{18,19}$. However, since most of the homogenous and giant hydrocarbon reservoirs have been developed and produced over the last century, development of more heterogeneous and challenging oil and gas fields has become the new trend for the industry. This needs advanced approaches for 
capturing further complexities in production forecasting which serves as the foundation for field development decision making ${ }^{20}$.

Heterogeneity has been a serious challenge for production forecasting as it dramatically affects the productivity of wells and jeopardizes the development plan. This problem may deteriorate the economics of tight reservoir development as expensive stimulations strain the benefit margins. Modelling such stimulations and more reliable forecasting will lead to better understanding of the project outcomes. In virtue of information technology (IT) advancement, some numerical models have been developed ${ }^{21,22,23}$, but they are highly time consuming to use and require a great deal of inputs.

Recently some authors have worked on forecasting the production from fractured wells. Hwang et al. $(2013)^{24}$ introduced a method that addresses the problem of having natural fractures -which is only one element of heterogeneity- by considering the fractures as a combined series of slab sources and by superposing the sources under several boundary or flow conditions. They claimed that, to reflect the heterogeneous nature of natural fractures, a stochastic method of generating discrete fracture networks should be adopted. The challenge, therefore, lies in data gathering and modelling the natural fractures. These authors suggested the Fractal Discrete Fracture Network model (FDFN), which incorporates the various scale-dependent data such as outcrops, logs, and cores, and creates more realistic natural fracture networks. This FDFN model is combined with the slab source model to build fracture networks first, and then the flow problem in the complex fracture systems is solved ${ }^{24}$. However, Hwang el al.'s choice of discarding other sources of heterogeneity to avoid further complications in forecasting leaves their work incapable of thoroughly addressing the effect of heterogeneity on well production performance.

Weng (2015) ${ }^{25}$ presented a comprehensive overview on modelling hydraulic fractures covering natural fracture impact and revealed the fact that precise prediction of detailed fracture geometry is still very challenging. He also concluded that even though many modelling approaches have been explored and models are developed to simulate complex fractures in the naturally fractured reservoir, most have some limitations, have limited focus, or lack full functionalities to simulate the entire fracturing process ${ }^{25}$. In 
parallel, MoradiDowlatabad and Jamiolahmady $(2015)^{26}$ developed a new equation that can predict multifractured horizontal wells performance under pseudo-steady state flow conditions in tight reservoirs. Holy and Ozkan (2016) ${ }^{27}$ presented a theoretically rigorous approach based on an anomalous diffusion model for the performance of fractured horizontal wells surrounded by a stimulated reservoir volume. The latter two methods, however, have not considered the impact of heterogeneity in the form of natural fractures. Thus, an empirical approach can provide a primary means for screening purposes or a secondary truthchecking controller.

This paper introduces a methodology called DCH for considering the heterogeneity impact on well production forecasting based on decline curve analysis. The method is empirical and applicable to multifractured horizontal wells in formations with permeabilities of less than $0.1 \mathrm{mD}$. A new parameter called heterogeneity impact factor (HIF) proposed by Parvizi et. al $(2017){ }^{28}$ is used in this approach to link the hydraulic fracturing and modelling with well test interpretation by quantifying the heterogeneity impact on hydraulic fracture performance. Successful application of the proposed DCH approach is validated against data from a Southern North Sea field using the most detailed three-dimensional history-matched reservoir simulation model.

\section{METHODOLOGY}

In order to forecast well production for heterogeneous reservoirs, two elements of forecasting and heterogeneity are established as below:

Forecasting. Arps $(1945)^{2}$ suggested the general expressions for production rate versus time as decline curve analysis. This method is focusing purely on the historical production data of the well to forecast its future production. Hyperbolic decline curve is one of these empirical formulas and can be calculated as:

$\mathrm{q}(\mathrm{t})=\mathrm{q}_{\mathrm{i}} /\left(1+\mathrm{b} \times \mathrm{D}_{\mathrm{i}} \times \mathrm{t}\right)^{1 / \mathrm{b}}$

Eq. 1 
where $b$ and $D_{i}$ are scaling constants and $q_{i}$ is the initial well production rate. The value of $b$ is in the range of zero to 1 . Bahadori (2012) ${ }^{29}$ introduced a practical workflow to arrive at an appropriate estimation of nominal (initial) decline rate, as well as the Arp's decline-curve exponent. Arp's DCA formulation has yet to be modified for heterogeneous reservoirs in such a way that it captures the impact of heterogeneity and predicts the production of other wells. Therefore, the heterogeneity effect on well performance should first be quantified.

Heterogeneity Impact Factor (HIF). Based on the results of well test analysis (WTA) and net pressure match (NPM), Parvizi et al. (2015b, 2017) ${ }^{28,30}$ introduced a new parameter called the WTA/NPM ratio or heterogeneity impact factor (HIF) which is a quantitative measure of the impact of heterogeneity on the performance of a well. It is calculated based on the induced fracture dimensions and conductivity discrepancy between interpreted post-fractured well test and the observed fracturing performance during operation. A brief description of HIF and its calculation is provided here. A complete account of this parameter can be found in Ref. 28 and 30.

In order to calculate HIF, surface conductivities, as a measure of hydraulic fracture volume times permeability, are defined as follows:

$\left.\mathrm{SC}\right|_{\mathrm{WTA}}=\sum_{\mathrm{i}=1}^{\mathrm{n}} 2 \mathrm{x}_{\mathrm{f}} \times \mathrm{h}_{\mathrm{f}} \times \mathrm{K}_{\mathrm{f} \cdot \mathrm{W}}$

$\left.S C\right|_{N P M}=\sum_{i=1}^{m} 2 x_{f} \times h_{f} \times K_{f} \cdot w$

where SC is surface conductivity, WTA is well test analysis (post-frac well test), NPM is main fracture net pressure match, $\mathrm{n}$ is the number of hydraulic fractures that are assumed for well test match, $\mathrm{m}$ is the number of hydraulic fractures that are executed during hydraulic fracture operation, $\mathrm{x}_{\mathrm{f}}$ is hydraulic fracture half length, $\mathrm{h}_{\mathrm{f}}$ is hydraulic fracture height, $\mathrm{K}_{\mathrm{f}}$ is permeability of hydraulic fracture, and $\mathrm{w}$ is fracture width.

Then, HIF is calculated as: 
$\left.\mathrm{HIF}\right|_{\mathrm{WTA} / \mathrm{NPM}}=\left.\mathrm{SC}\right|_{\mathrm{WTA}} /\left.\mathrm{SC}\right|_{\mathrm{NPM}}$

where $\left.\mathrm{HIF}\right|_{\text {WTA/NPM }}$ denotes $\mathrm{WTA} / \mathrm{NPM}$ ratio or heterogeneity ratio.

Once the two elements of forecasting and HIF are established, the following workflow is applied to the data available from a field including the well production data to obtain an empirical formula defined as decline curve including the effect of heterogeneity $(\mathrm{DCH})$ :

a) Choose a well from the earliest development phase or an analogue field that has similar matrix permeability. The goal is to get the longest available historical production data for the well. Analogue fields should be similar to the targeted field in terms of porosity, permeability, fault regime, well trajectory stand-off from water contact, and other similar parameters. Such criteria needs to be discussed in multidisciplinary teams to highlight the nature of the different characterisations (if any) or development techniques and the consequences of such differences on the analysis outcomes.

b) Use hyperbolic decline formula and fit a curve to the historical data to obtain $\mathrm{q}_{\mathrm{i}}, \mathrm{b}$, and $\mathrm{D}_{\mathrm{i}}$ factors.

c) Calculate HIF for this well $\left(\mathrm{HIF}_{0}\right)$ using equations 2,3 , and 4 ; $\mathrm{HIF}_{0}=1$ is ideal for $\mathrm{DCH}$ calculation.

d) Calculate HIF for the other drilled and fractured wells or use HIF from analogue fields.

e) Using table 1, calculate the new $\mathrm{q}_{\mathrm{mi}}, \mathrm{b}$, and $\mathrm{D}_{\mathrm{mi}}$ for other wells based on calculated or assumed HIF values.

f) Use the following formula to forecast new well production:

$\mathrm{q}_{\mathrm{DCH}}(\mathrm{t})=\mathrm{q}_{\mathrm{mi}} /\left(1+\mathrm{b} \times \mathrm{D}_{\mathrm{mi}} \times \mathrm{t}\right)^{1 / \mathrm{b}}$

where $t$ is time of production, $\mathrm{q}_{\mathrm{DCH}}(\mathrm{t})$ is flow rate considering heterogeneity impact at time $t, \mathrm{q}_{\mathrm{mi}}$ is the modified initial rate taking HIF into account, and $\mathrm{D}_{\mathrm{mi}}$ is the modified decline constant taking HIF into account. 
The key assumption here is that the wells are not communicating with each other. In such a case DCH will overestimate the well production rates.

\section{RESULTS AND DISCUSSION}

DCH is an approach developed by deploying a simplified heterogeneity concept for a modified Arp's DCA. This empirical method is used to generate multi-fractured horizontal gas production profiles and is a complement to the workflows Clarkson (2013) ${ }^{31}$ reviewed for production data analysis of unconventional gas wells to meet the demand for a faster approach which also considers the significantly complicated heterogeneity impact on well performance.

Three key assumptions are made in the calculation of this empirical formula:

1) Length of the horizontal well is $3000 \mathrm{ft}$.

2) There are 3 to 5 hydraulic fractures in the well.

3) Average matrix permeability is about $0.1 \mathrm{mD}$.

Initially, 5 years of production data of 3 multi-fractured horizontal wells from a field in Southern North Sea was considered (Fig. 1). The well test data of these wells are tabulated in Table 2. Besides, the analysis of fracturing operation data and using net-pressure matching leads to the results given in Table 3 .

Using equations 2 to 4 , it is possible to calculate the heterogeneity ratios for each well (see Table 4). As it is clear in Table 4, Well 2 is considered as the reference well in the current investigation since the calculated HIF for this well is close to unity. Using Eq. 1, a hyperbolic decline curve is fitted to the gas production rate of Well 2 and extrapolated to forecast future production rates, as shown in Fig. 2. DCH calculations are shown in Table 5. The area between the two graphs in Fig. 2 is an indicator as to the matching suitability of the DCH method. In this case, DCH predictions have been compared against the predictions made by Eclipse ${ }^{32}$ reservoir simulation 
software, and there is about $4 \%$ difference between the cumulative gas production of the two predictors (See Table 7). This difference is mostly due to the exclusion of the well's production schedule in the DCH calculation. In case of making predictions on future forecasts of the same production schedule, this assumption is appropriate and the collected information from DCH is sufficient. In the high case in Table $5, \mathrm{D}_{\mathrm{i}}$ is multiplied by HIF to account for the increased depletion caused by the accelerated production. Using the DCH formula, predictions for well 1 and well 3 are calculated and shown in figures 3 and 4. The results obtained for wells 1 and 3 show acceptable and reasonable matches between the DCH prediction and the historical production data for cases where the performance of the well is significantly affected by its heterogeneity.

The proceeding phases of this field development can also be predicted faster by the DCH method than the high-powered numerical simulation. For example, in the next phase of this field development, another well was drilled and fractured. Although this well has production data for a short period (only 30 months) an attempt was made to compare the DCH prediction with the real production data. Table 6 shows the results of the well test and net pressure match analysis for this well. A quantitative comparison of the cumulative productions from $\mathrm{DCH}$ and numerical simulation using Eclipse is another indicator of the DCH prediction suitability. In this case, there was a negligible difference of about $3 \%$ between cumulative gas production predictions of the two predictors (Table 6 and Fig. 6). 
The DCH method is much faster both in terms of modelling preparation and simulation runtime than conventional 3D modelling methodologies (See Table 8). The fact that HIF is the only key parameter representing the heterogeneity impact, makes it very easy to run different scenarios and generate production profiles for uncertainty analysis.

HIF represents the influence of heterogeneity on well performance. A positive HIF value means well test interpretation exhibits presence of extra supports for production, considering the fact that well test reflects the overall remoter behaviour of well-reservoir interaction compared to netpressure-match result which is at the proximity of the well-fractures. Negative HIF displays lower support for well production due to heterogeneity. Thus, an attempt has been made to explore the relationship between the matched DCA parameters and HIF for the observed data of different wells.

The higher HIF corresponds to higher than expected observed initial production rates, and the data shows a direct proportion to WTA/NPM ratio. For a negative HIF, just multiplying DCA's initial production rate of base case by the WTA/NPM ratio led to a match of the corresponding well behaviour. For positive cases, this is more complicated as the depletion effect should be considered as well. When the initial rate is higher, the depletion is accelerated, and a faster decline is expected due to higher cumulative production. Hence, the DCA decline factor is also multiplied by the WTA/NPM ratio. This could match the well behaviour for positive HIF cases. Based on the well production data, DCH has been developed, and then the data for well 4, which has been drilled and completed in the proceeding phase of development, has been tested to see if DCH exhibits a reasonable match. It appeared that cumulative production data of well 4 is only $3 \%$ different from the corresponding numerical simulation results which are assumed as reference for comparison with the DCH results. 
It should be noted that the objective this approach is to have a faster method to capture a wider range of production forecasts in order to model the massive uncertainty of well production forecasting due to heterogeneity for undrilled wells and lay the foundation for such works. For this objective, a higher degree of error is acceptable as the general pattern of hundreds of forecasts shall remain quite unaffected due to slight over- or under-predictions. The proposed DCH approach is recommended based on observed field data in tight sand reservoirs and it is esteemed that more research can be exercised to extend the idea for the other type of formations such as shale reservoirs where the influence of transient behaviour is dominant.

It is worth mentioning that the detailed physics for interaction of induced fractures with existing natural fractures are not modelled as conventional simulation techniques such as finite difference applied here does not cover such details. The overall behaviour of the wells, though, has been modelled, because historical data was available. The hydraulic fracture and matrix properties have been tuned slightly to capture the overall behaviour and match the well performance. This has no effect on the results because of the order of details.

\section{CONCLUSIONS}

The proposed DCH approach provides a sufficiently representative trend of the production performance of the wells, and as such can be used to forecast and make future decisions via a fully empirical method that abstains from costly and time-consuming numerical simulations. The accuracy is apparent in the similarity between the DCH predictions with Eclipse predictions for the gas production rate. In these estimations, the DCH prediction deviates by a maximum of $15 \%$ from predictions of numerical simulation using Eclipse. This margin of error is reasonable in comparison to the substantial reduction of lengthy simulation procedures. Given a larger 
quantity of information, the algorithms can be tuned to act more robustly by considering more parameters when modelling the heterogeneity of the reservoirs.

\section{AUTHOR INFORMATION}

\section{Corresponding author}

*E-mail: s.rezaei-gomari@tees.ac.uk

\section{Notes}

The authors declare no competing financial interest

\section{ACKNOWLEGMENTS}

The authors would like to thank Paul Arkley, Paul Jeffs, Abhimanyoo Kohok, Alex Kay, Andrea Turner, Wei-cher Feng, Sina Monfared and Babak Sami Vand for their useful insights and discussions.

\section{NOMENCLATURE}

b Scaling constant in decline curve analysis

DCA Decline Curve Analysis

DCH Decline Curve including Heterogeneity

$\mathrm{D}_{\mathrm{i}} \quad$ Scaling constant in decline curve analysis

$\mathrm{D}_{\mathrm{mi}} \quad$ Modified decline constant taking into account $\mathrm{Hr}$

FDFN Fractal Discrete Fracture Network

$\mathrm{Hr} \quad$ Heterogeneity ratio

k Permeability

$\mathrm{K}_{\mathrm{f} . \mathrm{W}} \quad$ Connectivity of hydraulic fracture

$\mathrm{m} \quad$ Number of hydraulic fractures that are executed during hydraulic fracture operation

$\mathrm{mD} \quad$ Milli darcy 


$\begin{array}{ll}\text { MMSFD } & \text { Million standard cubic feet per day } \\ \text { MSCFD } & \text { Thousands standard cubic feet per day } \\ \mathrm{n} & \text { Number of hydraulic fractures that are assumed for well test match } \\ \mathrm{NPM} & \text { Net Pressure Match } \\ \mathrm{q}_{\mathrm{DCH}}(\mathrm{t}) \quad \text { flow rate considering heterogeneity impact at time t } \\ \mathrm{q}_{\mathrm{mi}} & \text { modified initial rate taking into account } \mathrm{Hr} \\ \mathrm{S} & \text { Skin } \\ \mathrm{SC} & \text { Surface Conductivity } \\ \mathrm{W} & \text { Fracture width } \\ \text { WTA } & \text { Well Test Analysis } \\ \mathrm{x}_{\mathrm{f}} & \text { Fracture half-length }\end{array}$

\section{REFERENCES}

(1) Zhu, D., Magalhaes, F., Valkó, P.P. (2007, January 1). Predicting the Productivity of MultipleFractured Horizontal Gas Wells. Society of Petroleum Engineers. doi:10.2118/106280-MS

(2) Arps, J. J. (1945, December 1). Analysis of Decline Curves. Society of Petroleum Engineers. doi:10.2118/945228-G

(3) Fetkovich, M. J. (1980, June 1). Decline Curve Analysis Using Type Curves. Society of Petroleum Engineers. doi:10.2118/4629-PA

(4) Arps, J. J. (1956, January 1). Estimation of Primary Oil Reserves. Society of Petroleum Engineers.

(5) Fetkovich, M. J., Vienot, M. E., Bradley, M. D., \& Kiesow, U. G. (1987, December 1). Decline Curve Analysis Using Type Curves: Case Histories. Society of Petroleum Engineers. doi:10.2118/13169-PA 
(6) Fetkovich, M. J., Fetkovich, E. J., \& Fetkovich, M. D. (1996, February 1). Useful Concepts for Decline Curve Forecasting, Reserve Estimation, and Analysis. Society of Petroleum Engineers. doi:10.2118/28628-PA

(7) Marhaendrajana, T., \& Blasingame, T. A. (2001, January 1). Decline Curve Analysis Using Type Curves - Evaluation of Well Performance Behavior in a Multiwell Reservoir System. Society of Petroleum Engineers. doi:10.2118/71517-MS

(8) Pratikno, H., Rushing, J. A., \& Blasingame, T. A. (2003, January 1). Decline Curve Analysis Using Type Curves - Fractured Wells. Society of Petroleum Engineers. doi:10.2118/84287-MS

(9) Li, K., \& Horne, R. N. (2005, June 1). A Decline Curve Analysis Model Based on Fluid Flow Mechanisms. Society of Petroleum Engineers. doi:10.2118/83470-PA

(10) Li, K., \& Horne, R. N. (2007, February). Comparison and verification of production prediction models. Journal of Petroleum Science and Engineering 55, 213-220.

(11) Ozkan, E., Raghavan, R., \& Joshi, S. D. (1989, December 1). Horizontal Well Pressure Analysis. Society of Petroleum Engineers. doi:10.2118/16378-PA

(12) Babu, D. K., \& Odeh, A. S. (1989, November 1). Productivity of a Horizontal Well. Society of Petroleum Engineers. doi:10.2118/18298-PA

(13) Yildiz, T., \& Bassiouni, Z. A. (1990, January 1). Transient Pressure Analysis In PartiallyPenetrating Wells. Society of Petroleum Engineers. doi:10.2118/21551-MS

(14) Butler, R.M., Dargie, B. \& Petroleum Society of CIM (1994). Horizontal Wells for The Recovery of Oil, Gas, and Bitumen. Calgary: Petroleum Society, Canadian Institute of Mining, Metallurgy \& Petroleum.

(15) Ozkan, E., Sarica, C., Haciislamoglu, M., \& Raghavan, R. (1995, March 1). Effect of Conductivity on Horizontal Well Pressure Behavior. Society of Petroleum Engineers. doi:10.2118/24683-PA 
(16) Furui, K., Zhu, D., \& Hill, A. D. (2003, August 1). A Rigorous Formation Damage Skin Factor and Reservoir Inflow Model for a Horizontal Well. Society of Petroleum Engineers. doi:10.2118/84964-PA

(17) Kamkom, R., \& Zhu, D. (2006, January 1). Generalized Horizontal Well Inflow Relationships for Liquid, Gas, or Two-Phase Flow. Society of Petroleum Engineers. doi:10.2118/99712-MS

(18) Wei, Y., \& Economides, M. J. (2005, January 1). Transverse Hydraulic Fractures from a Horizontal Well. Society of Petroleum Engineers. doi:10.2118/94671-MS

(19) Daal, J. A., \& Economides, M. J. (2006, January 1). Optimization of Hydraulically Fractured Wells in Irregularly Shaped Drainage Areas. Society of Petroleum Engineers. doi:10.2118/98047MS

(20) Parvizi, H., Rezaei-Gomari, S., Nabhani, F., Dastkhan, Z., \& Feng, W. C. (2015, June 1). A Practical Workflow for Offshore Hydraulic Fracturing Modelling: Focusing on Southern North Sea. Society of Petroleum Engineers. doi:10.2118/174339-MS

(21) Gu, Q. \& Hoo, K. A. (2014, May 19). Evaluating the Performance of a Fracturing Treatment Design. Ind. Eng. Chem. Res. 53 (25), pp 10491-10503. doi: 10.1021/ie404134n

(22) Zhang, R., Zhang, L., Wang, R., Zhao, Y., \& Huang, R. (2016, October 10). Simulation of a Multistage Fractured Horizontal Well with Finite Conductivity in Composite Shale Gas Reservoir through Finite-Element Method. Energy Fuels, 30 (11), pp 9036-9049. doi: 10.1021/acs.energyfuels.6b01565

(23) Patwardhan, S. D., Famoori, F., Gunaji, R. G., \& Govindarajan S. K. (2014, December 1). Simulation and Mathematical Modeling of Stimulated Shale Gas Reservoirs. Ind. Eng. Chem. Res.. 53 (51), pp 19788-19805. doi: 10.1021/ie501116j

(24) Hwang, Y., Lin, J., Zhu, D., \& Schechter, D. (2013, March 26). Predicting Fractured Well Performance in Naturally Fractured Reservoirs. International Petroleum Technology Conference. doi:10.2523/IPTC-17010-MS 
(25) Weng, X. (2015). Modeling of complex hydraulic fractures in naturally fractured formation. Journal of Unconventional Oil and Gas Resources, Volume 9, March 2015, Pages 114-135. http://dx.doi.org/10.1016/j.juogr.2014.07.001

(26) MoradiDowlatabad, M., \& Jamiolahmady, M. (2015, September 8). Novel Approach for Predicting Multiple Fractured Horizontal Wells Performance in Tight Reservoirs. Society of Petroleum Engineers. doi:10.2118/175446-MS

(27) Holy, R. W., \& Ozkan, E. (2016, May 5). A Practical and Rigorous Approach for Production Data Analysis in Unconventional Wells. Society of Petroleum Engineers. doi:10.2118/180240MS

(28) Parvizi, H., Rezaei-Gomari, S., Nabhani, F., \& Turner, A. (2017) Evaluation of heterogeneity impact on hydraulic fracturing performance. Journal of Petroleum Science and Engineering. Volume 154, June 2017, Pages 344-353. https://doi.org/10.1016/j.petrol.2017.05.001

(29) Bahadori, A. (2012). Analysing gas well production data using a simplified decline curve analysis method. Chemical Engineering Research and Design. Volume 90, Issue 4, Pages 541547. http://dx.doi.org/10.1016/j.cherd.2011.08.014

(30) Parvizi, H., Rezaei-Gomari, S., Nabhani, F., Turner, A., \& Feng, W. C. (2015, June 1). Hydraulic Fracturing Performance Evaluation in Tight Sand Gas Reservoirs with High Perm Streaks and Natural Fractures. Society of Petroleum Engineers. doi:10.2118/174338-MS

(31) Clarkson, C. R. (2013). Production data analysis of unconventional gas wells: Review of theory and best practices, International Journal of Coal Geology, Volumes 109-110, 1, Pages 101-146, https://doi.org/10.1016/j.coal.2013.01.002.

(32) Schlumberger Limited (2014). Eclipse 2014 [Reservoir Simulator software].

\section{Tables}


Table 1. DCH parameters and formula

\begin{tabular}{cccc}
\hline $\begin{array}{c}\text { DCH } \\
\text { Parameters }\end{array}$ & $\begin{array}{c}\text { Fitted curve } \\
\text { parameters as } \\
\text { Reference }\end{array}$ & $\begin{array}{c}\text { Formula for Low } \\
\text { Case (if HIF }<1)\end{array}$ & $\begin{array}{c}\text { Formula for High } \\
\text { Case (if HIF }>1)\end{array}$ \\
\hline Modified $\mathrm{D}_{\mathrm{mi}}$ & $\mathrm{D}_{\mathrm{i}}$ & $\mathrm{D}_{\mathrm{i}}$ & $\mathrm{D}_{\mathrm{i}}{ }^{*} \mathrm{HIF}$ \\
\hline Modified $\mathrm{q}_{\mathrm{mi}}$ & $\mathrm{q}_{\mathrm{i}}$ & $\mathrm{q}_{\mathrm{i}}{ }^{*} \mathrm{HIF}$ & $\mathrm{q}_{\mathrm{i}}{ }^{*} \mathrm{HIF}$ \\
\hline $\mathrm{b}$ & $\mathrm{b}$ & $\mathrm{b}$ & $\mathrm{b}$ \\
\hline
\end{tabular}

Table 2. Well test analysis per well

\begin{tabular}{ccccc}
\hline Well & $\begin{array}{c}\text { Kf.w (Frac) } \\
\text { mD.ft }\end{array}$ & $\begin{array}{c}\text { Number of } \\
\text { Fractures }\end{array}$ & $\begin{array}{c}\text { Fracture Half } \\
\text { Length }(\mathrm{ft})\end{array}$ & $\begin{array}{c}\text { Fracture Height } \\
(\mathrm{ft})\end{array}$ \\
\hline 1 & 1000 & 4 & 200 & 250 \\
\hline 2 & 500 & 3 & 200 & 250 \\
\hline 3 & 2500 & 4 & 300 & 250 \\
\hline
\end{tabular}

Table 3. Net pressure match per fracture

\begin{tabular}{c|ccc}
\hline \multirow{2}{*}{ Well } & Kf.w (Frac) mD.ft & Fracture Half Length (ft) & Fracture Height (ft) \\
\hline \multirow{4}{*}{1} & 632 & 175 & 75 \\
\cline { 2 - 4 } & 403 & 210 & 250 \\
\cline { 2 - 4 } & 2169 & 350 & 150 \\
\cline { 2 - 4 } & 2106 & 220 & 230 \\
\hline \multirow{4}{*}{2} & 2008 & 150 & 220 \\
\cline { 2 - 4 } & 195 & 200 & 60 \\
\cline { 2 - 4 } & 353 & 150 & 110 \\
\cline { 2 - 4 } & 1227 & 252 & 198 \\
\hline \multirow{3}{*}{3} & 463 & 320 & 140 \\
\cline { 2 - 4 } & 1102 & 260 & 230 \\
\cline { 2 - 4 } & 1088 & 220 & 220 \\
\hline
\end{tabular}




\begin{tabular}{l|lll}
\hline \multirow{2}{*}{} & 1840 & 250 & 180 \\
\cline { 2 - 4 } & 2478 & 200 & 240 \\
\hline
\end{tabular}

Table 4. Heterogeneity ratio for each well

\begin{tabular}{cc}
\hline Well & HIF \\
\hline 1 & 0.63 \\
2 & 1.04 \\
\hline 3 & 1.74 \\
\hline
\end{tabular}

Table 5. DCH Calculation for wells 1, 2 and 3

\begin{tabular}{cccc}
\hline $\begin{array}{c}\text { DCH } \\
\text { Parameters }\end{array}$ & $\begin{array}{c}\text { Fitted curve } \\
\text { parameters as } \\
\text { Reference }\end{array}$ & $\begin{array}{c}\text { Formula for Low } \\
\text { Case HIF }=0.63\end{array}$ & $\begin{array}{c}\text { Formula for High } \\
\text { Case HIFr=1.74 }\end{array}$ \\
\hline Modified $\mathrm{D}_{\mathrm{mi}}$ & $\mathrm{D}_{\mathrm{i}}=4.20 \%$ & $\mathrm{D}_{\mathrm{i}}=4.20 \%$ & $\mathrm{D}_{\mathrm{i}}^{*} \mathrm{HIF}=7.31 \%$ \\
\hline Modified $\mathrm{q}_{\mathrm{mi}}$ & $\mathrm{q}_{\mathrm{i}}=25000$ MSCFD & $\mathrm{q}_{\mathrm{i}}{ }^{*} \mathrm{HIF}=15750$ & $\mathrm{q}_{\mathrm{i}}^{*} \mathrm{HIF}=43500$ \\
$\mathrm{~b}$ & $\mathrm{~b}=0.70$ & $\mathrm{MSCFD}$ & $\mathrm{MSCFD}$ \\
\hline
\end{tabular}

Table 6. The well test and net pressure match analysis results for Well \#4 DCH calculation

\begin{tabular}{|c|c|c|c|c|c|c|}
\hline \multicolumn{4}{|c|}{ Well test analysis for well \#4 } & \multicolumn{3}{|c|}{ Net pressure match per fracture } \\
\hline $\begin{array}{c}\mathrm{K}_{\mathrm{f} \cdot \mathrm{w}}(\text { Frac }) \\
\mathrm{mD} \cdot \mathrm{ft}\end{array}$ & $\begin{array}{c}\text { No. of } \\
\text { Fractures }\end{array}$ & $\begin{array}{c}\text { Fracture } \\
\text { Half Length } \\
\text { (ft) }\end{array}$ & $\begin{array}{c}\text { Fracture } \\
\text { Height (ft) }\end{array}$ & $\begin{array}{c}\text { Fracture } \\
\text { Half Length } \\
\text { (ft) }\end{array}$ & $\begin{array}{c}\text { Fracture } \\
\text { Height (ft) }\end{array}$ & $\begin{array}{c}\mathrm{K}_{\mathrm{f} \cdot \mathrm{W}}(\mathrm{Frac}) \\
\text { mD.ft }\end{array}$ \\
\hline \multirow{2}{*}{1220} & \multirow{2}{*}{3} & \multirow{2}{*}{202} & \multirow{2}{*}{150} & 420 & 150 & 2489 \\
\hline & & & & 350 & 180 & 1512 \\
\hline
\end{tabular}




\begin{tabular}{l|lll}
\hline & 580 & 115 & 601 \\
\cline { 2 - 4 } & 425 & 130 & 453 \\
\hline
\end{tabular}

Table 7. Cumulative gas production of the predictors and the difference

\begin{tabular}{ccccc}
\hline Predictions & Well 1 & Well 2 & Well 3 & Well 4 \\
\hline Cumulative Gas Production DCH (Bcf) & 18.3 & 29.5 & 34.7 & 10.3 \\
\hline Cumulative Gas Production Eclipse (Bcf) & 15.5 & 28.3 & 32.5 & 10.6 \\
\hline Difference (\%) & $15 \%$ & $4 \%$ & $6 \%$ & $-3 \%$ \\
\hline
\end{tabular}

Table 8. Comparison of the timing for DCH versus a conventional methodology

\begin{tabular}{cc}
\hline Activities & Time \\
\hline DCH study and modelling preparation & 2 weeks \\
\hline DCH run time & $<1$ second \\
\hline 3D modelling preparation & 4 months \\
\hline Eclipse run time & 3 hours \\
\hline
\end{tabular}

\section{Figures}




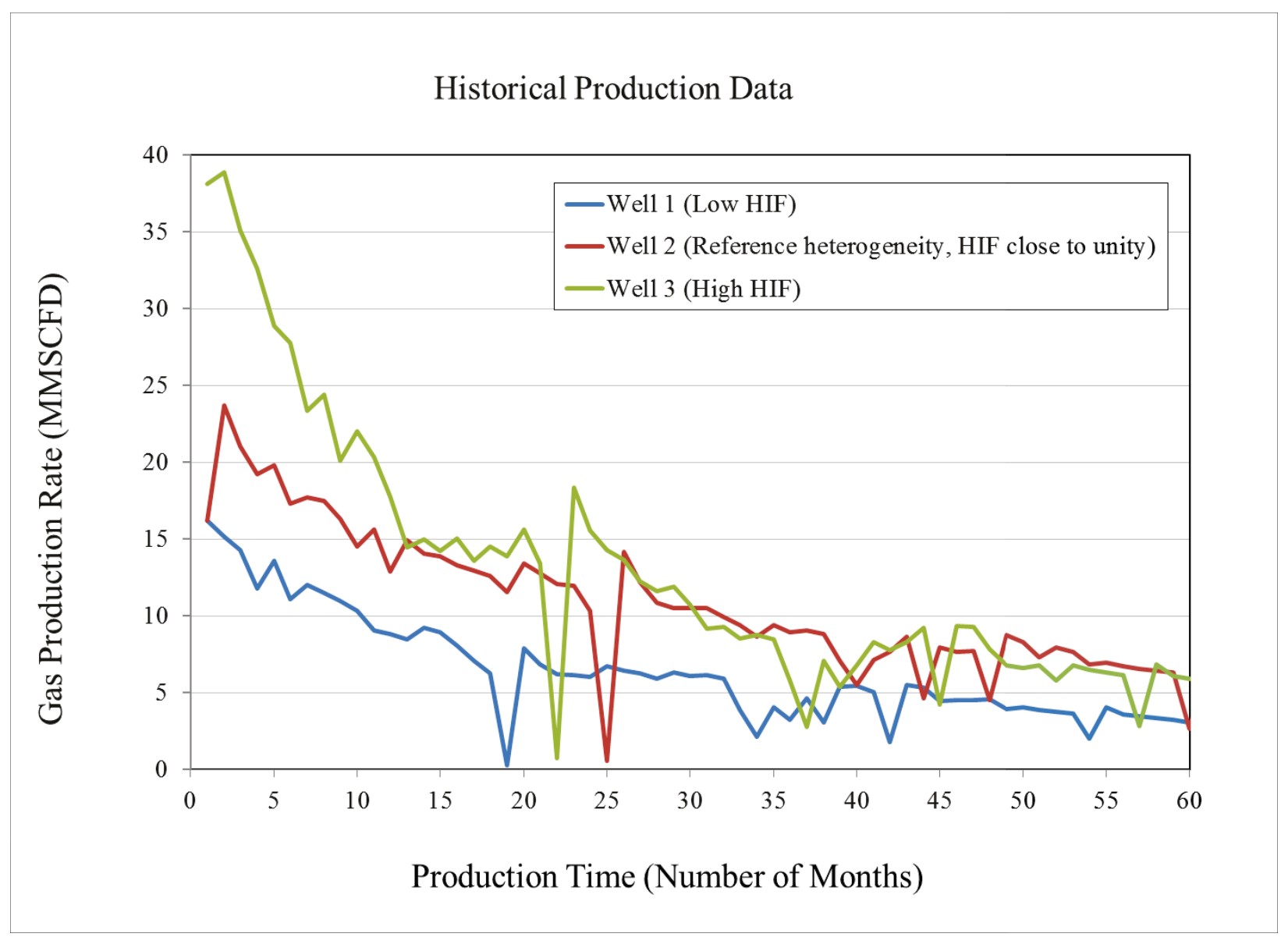

Figure 1. Five-year well production data of three multi-fractured horizontal wells 


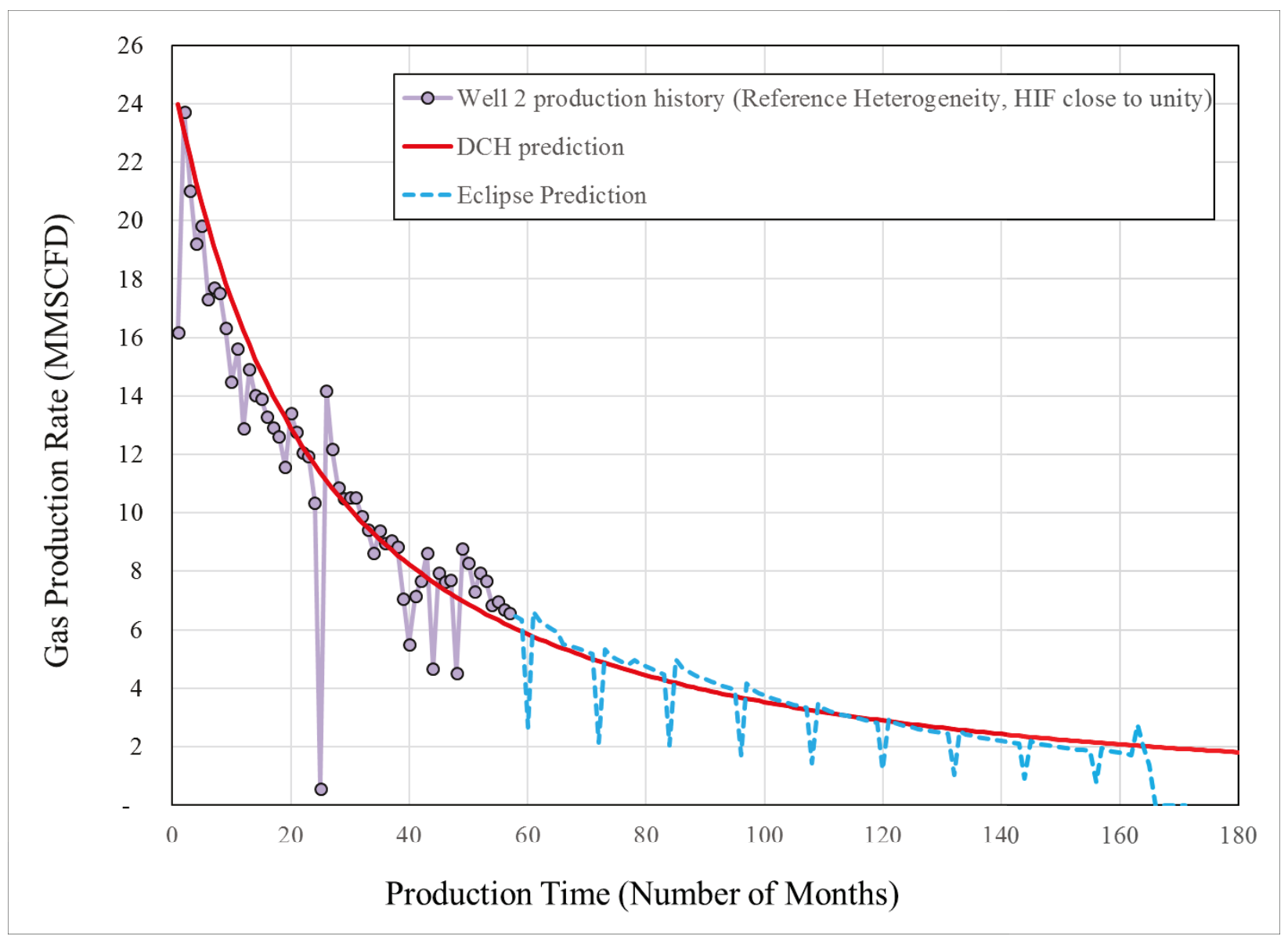

Figure 2. Well 2 historical production rates matched with DCH and Eclipse predictions 


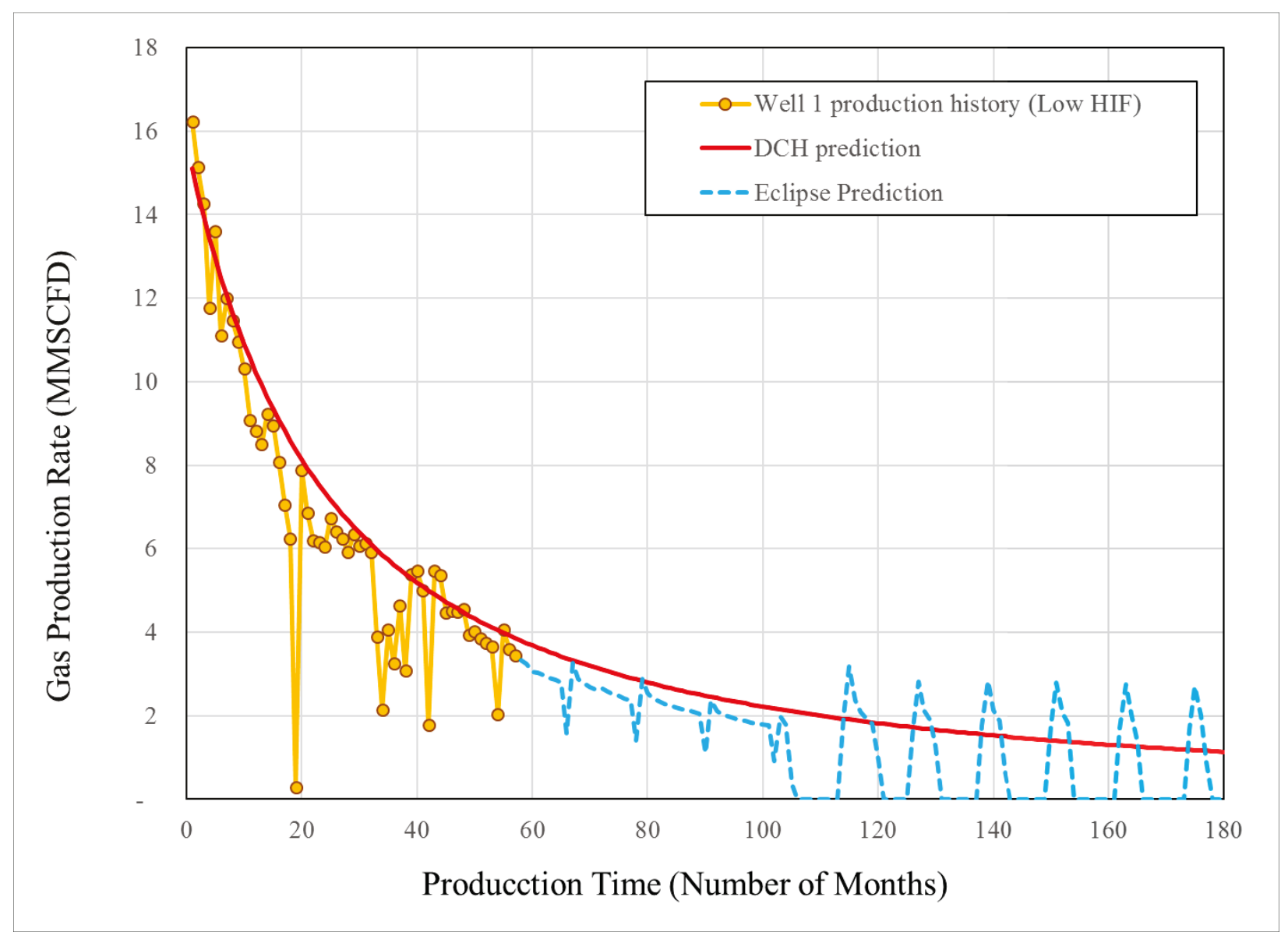

Figure 3. DCH matched with Well 1 historical production rates and Eclipse predictions 


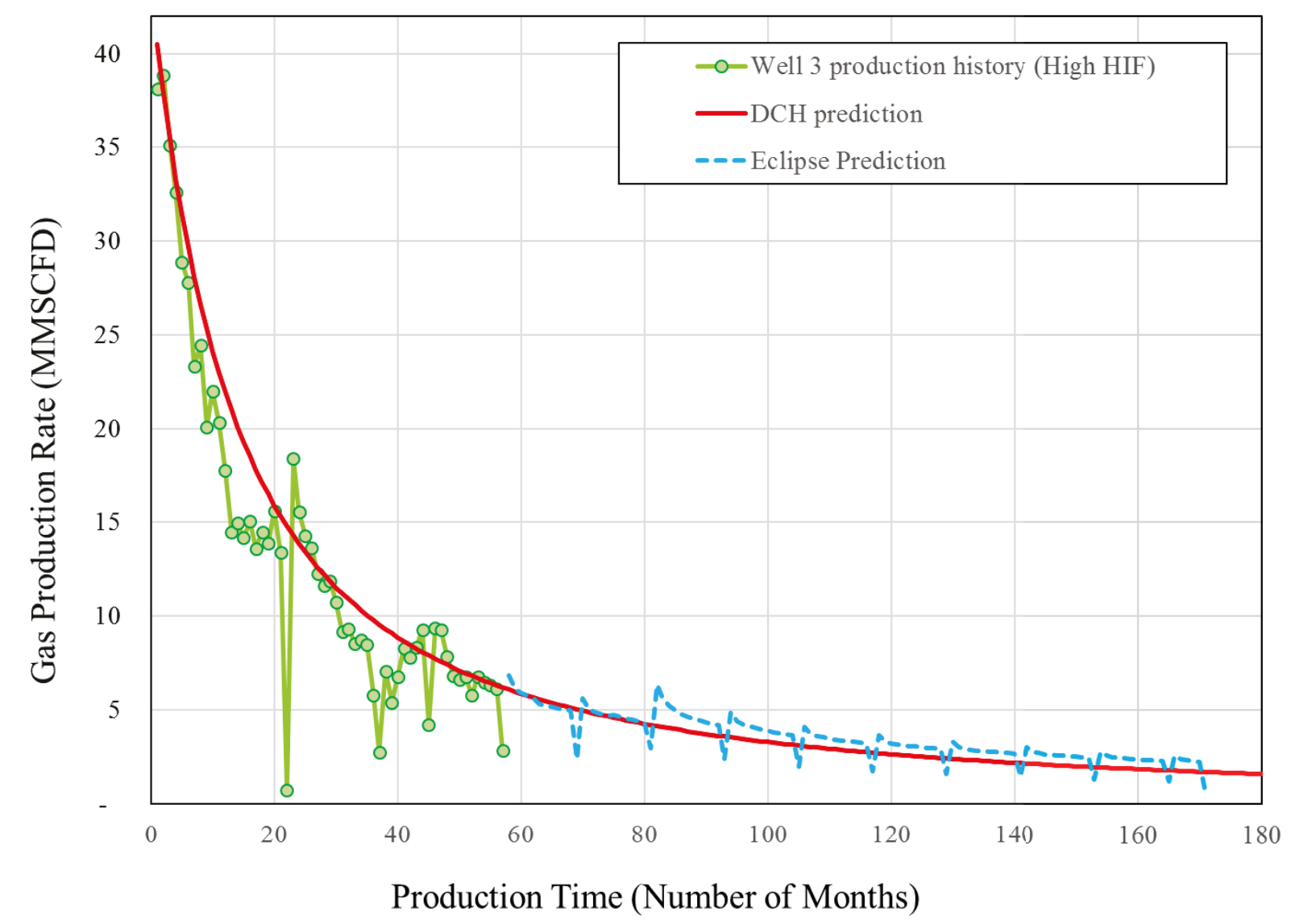

Figure 4. DCH matched with Well 3 historical production rates and Eclipse predictions 


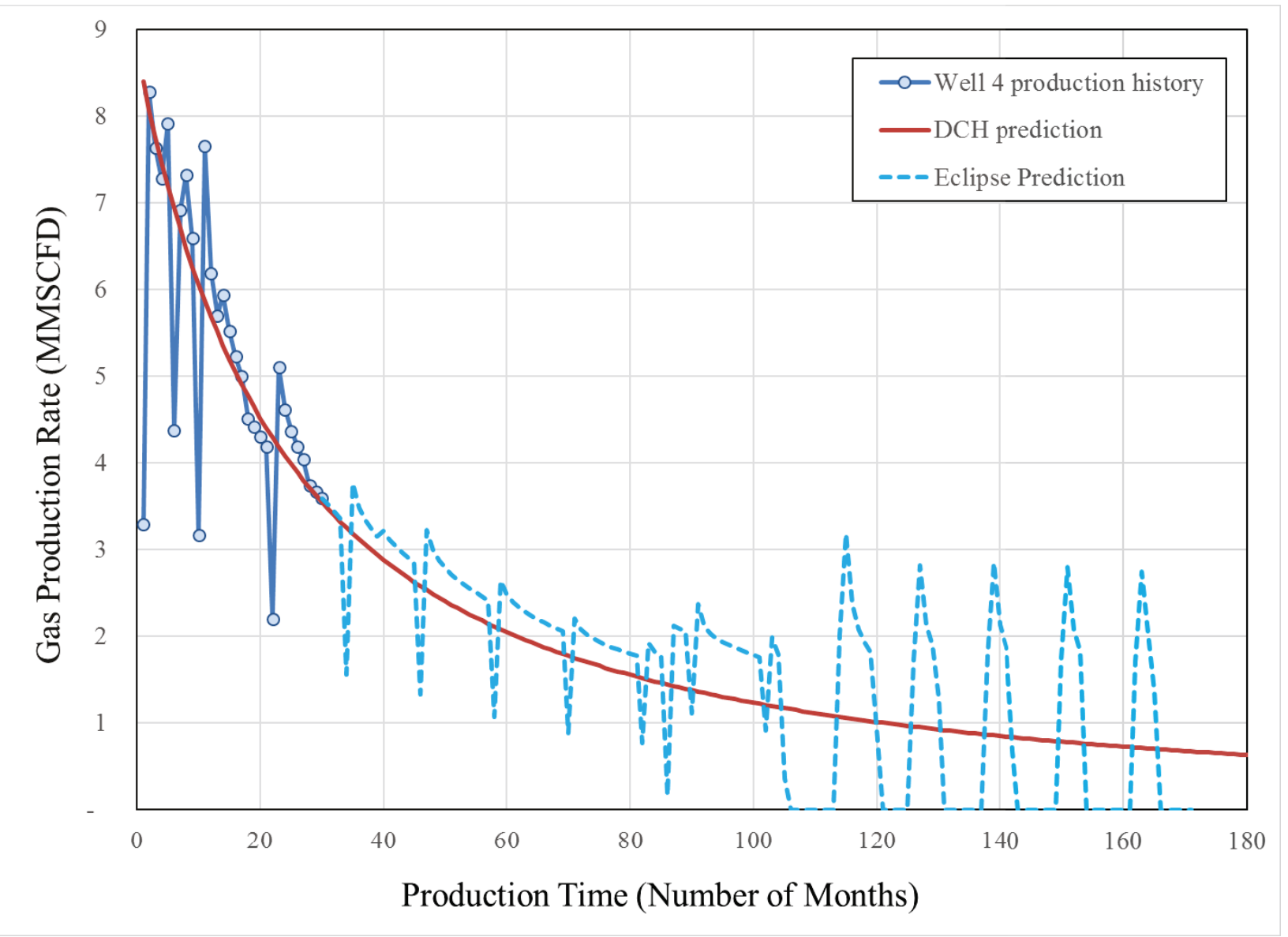

Figure 5. DCH matched with Well 4 historical production rates and Eclipse predictions 


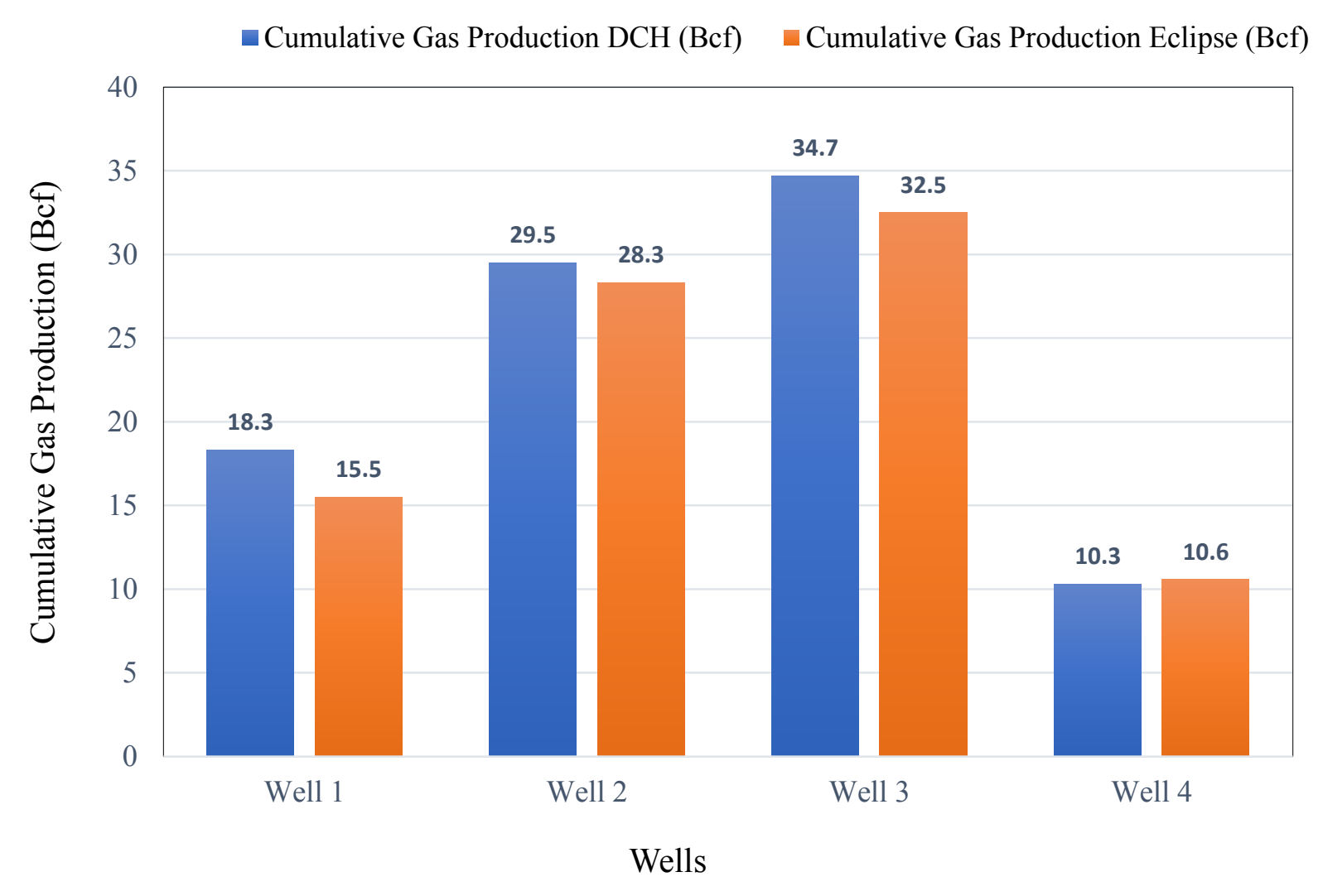

Figure 6. DCH Cumulative gas production versus Eclipse predictions 